\title{
Inflation Targeting and Inflation Indicators: The Case of Inflation Targeting in South Africa
}

\author{
Leward Jeke \\ Department of Economics, University of Fort Hare, East London Campus, \\ Private Bag X1314 Alice, 5700, South Africa. \\ Email: lewardjeke@gmail.com \\ Dr R Ncwadi \\ Department of Economics \& Economic History, P O Box 77000 \\ Nelson Mandela Metropolitan University, Port Elizabeth 6031, South Africa \\ Email: ronney.ncwadi@nmmu.ac.za
}

Doi:10.5901/mjss.2014.v5n10p136

\section{Abstract}

This paper uses testable effects of each of the inflation indicators to the rate of inflation using econometrics tools to find that they have a long run trend with the rate of inflation in South Africa. Empirical results indicate that each of the indicator variables has a long run relationship with the rate of inflation. The major conclusion is that inflation indicator variables like money supply (M3), oil price, gold price, total employment, interest rates, exchange rates and output growth can be useful inflation indicators in targeting the future trends of inflation in South Africa.

Keywords: Inflation Indicators, Cointegration, South Africa, Central Bank and Inflation Targeting.

\section{Introduction}

Monetary policy has been under public scrutiny and has resulted to changes in its conduct and design in the past few decades. Due to countries' trade and integration, monetary policy has been focused to the main motive of low inflation and price stability. As a result of this, a number of developing countries have adopted different monetary policy actions through the use of prices of gold, interest rates, exchange rate pegging, monetary targeting, price level targeting, and price of oil and so on to hedge themselves from high price levels.

Inflation targeting, pioneered in New Zealand, has a profound impact on the economic policy in developing countries like South Africa. According to Bernanke et al (1997), the hallmark of inflation targeting is the announcement by the government, the central bank, or some combination of the two that in the future the central bank will strive to hold inflation at or near some numerically specified level. Most economists concur to this view of price stability and that low inflation is better for a healthier economy than high rates of inflation. For this reason, most industrialized and nonindustrialized countries have adopted inflation targeting as a monetary policy. A study by Epstein (2007) reviewed that since the inception of inflation targeting, inflation has come down worldwide. Countries that adopted inflation targeting as a monetary policy experienced low inflation rate figures.

South Africa (SA) is an open economy that is subject to exogenous shocks which affect inflation. These shocks are a result to changes in the inflation indicator variables that include the price of gold, the exchange rates, interest rates, the employment rates, the total output, the money supply (M3) and the price of oil (SARB, Quarterly Bulletin, October 1997). In an inflation targeting regime, a superb example may be a sudden rise in oil prices or drought that alters the rate of inflation resulting in a deviation from the targeted range. These aggregate supply shocks such as oil price shocks present a thornier monetary policy problem. In this regard, a well implemented inflation-targeting regime need not strongly constrain the ability of the monetary authorities to respond to such supply shocks. Most often the rate of inflation rise owing to the fluctuations in the inflation indicator variables.

The targeted range has been missed at different time intervals since its inauguration as a monetary policy in South Africa. This has since presented several asymmetries which are also costly for employment and growth. The South African inflation indicators are therefore the genesis of the study to investigate ways in which inflation can be combated. An understanding of these inflation indicators driving and perpetuating inflation in South Africa should shed light on the 
SARB's control over the inflation process and the relative efficacy of alternative monetary policy frameworks and instruments.

\section{Overview of the Inflation Targeting Regime in South Africa}

South Africa has adopted inflation targeting since year 2000. Although inflation targeting has been criticized by many researchers through its apparent inability to reduce the so-called sacrifice ratio, the unemployment costs of fighting inflation, it has been an essential tool to the South African economy development as it has been anchoring long-run inflation expectations. Burger et al (2009) studies whether or not the official inflation targeting regime in South Africa improves inflation performance compared to the unofficial (implicit) inflation target regime in South Africa of the period 1990-2000. The paper argues that improved inflation performance is not only measured in terms of a lower inflation rate. In South Africa, since the implementation of inflation targeting, the CPIX exceeded its $6 \%$ upper bound in 29 of the 72 months between January 2002 (the first month of the first year that inflation had to be within its target range given a 24 month policy lag) and December 2007 (Burger et al, 2009). This has seen the MPC and the Governor of the SARB to work consistently to control the rate of inflation back to the targeted range.

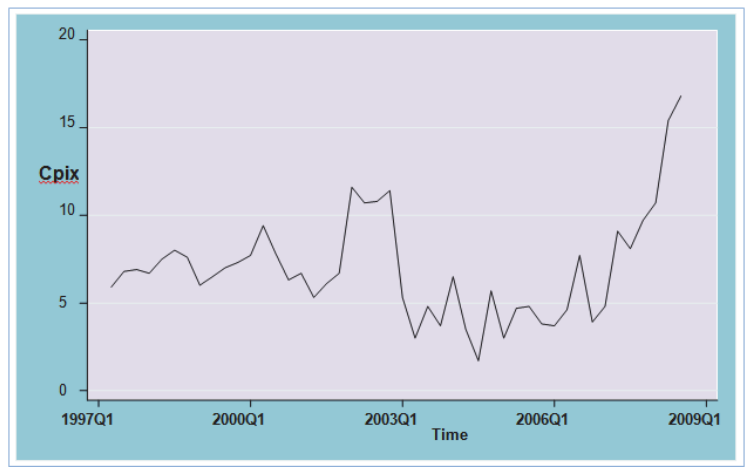

Figure 1: Trend of the inflation rate from 1997Q2 to 2008Q3 (Source: SSA data)

With reference to the on-going quest for low rate of inflation in different countries, many concepts have been proposed and promoted before. For example, the use of inflation targeting and other policy alternatives that include exchange rate targeting, real targeting (Epstein 2003), monetary aggregates (Svensson 2007), price level targeting (Hagen et al, 2001) etc has helped to lower the rate of inflation. Some of these concepts took 'flavour of the month' status and quickly vanished off the shelves, while others had significant impacts on monetary policy efficiency and success and are still being used to date. Inflation targeting can also be seen as one of these proposals, even though its impact and whether it will remain in use for a long time, is yet to be evaluated. This study draws reference to this perspective, where its main objective is to evaluate the actual impact of inflation targeting using inflation indicators in South Africa.

The South African economy has been undergoing some inflation oscillations at different times from the second quarter of year 1997 to the third quarter of the year 2008 (period under study). It can be deduced that inflation target of $3 \%-6 \%$ was achieved successively from the first quarter of 2003 to the first quarter of year 2006 and first quarter of year 2007. This has since improved the credibility and effectiveness of South Africa's macro-economic policy. The trend however, has shown a marked improvement in the early years of inflation targeting and the years after 2006 has shown a loom in the rate of inflation out of the target range.

\section{Review of Related Literature}

A number of studies have investigated both theoretically and empirically an assessment of inflation targeting framework as a monetary policy regime. This ranges from different methodology like Traditional Taylor rule (TTR) and some style rules which are different. Best rules were selected by both the Fisher test and the information criteria in some of the studies whereby the estimation methods depended on the result of the exogeneity, autocorrelation and heteroscedasticity. Some of papers discuss the issues of inflation targeting in developing countries, why it works and how to make it work better, conditions for successful inflation targeting, the reasons why these countries switch to inflation targeting regime, and the extent to which these conditions are satisfied in developing and developed countries. Others 
evaluate inflation targeting as a monetary policy strategy in particular countries by offering empirical models to assess the feasibility of inflation targeting in these countries. Some studies have been carried out to evaluate inflation indicators in different countries to check whether the root to inflation going out of the range is as a result of failure to incorporate the indicators very well. Different inflation indicators have been used for different countries in the process of evaluation. This study empirically evaluates the inflation indicators of South Africa and checks whether these indicators move in tandem with the rate of inflation.

The leading indicators typically incorporate information on selected prices to augment or replace information on economic slack. The prices selected are usually key commodity prices that fluctuate more or less continuously in response to changing economic conditions. Most often someone may expect inflation to increase or to drop and may base these expectations through various approaches besides the use of inflation indicators to forecasting inflation. Research done by Cecchetti et al 1995 reviewed that indicators must not be used in isolation as they can provide a limited predictive power. He further argued that the real variables such as unemployment, prices of gold and oil are correlated with inflation at horizons of 1 or 2 years, but not at horizons of 3 to 4 years. This paper incorporated all the indicators and some of the indicators were lagged.

According to research done by Cecchetti, Steindel and Chu (2000), the forecasts based on indicators in the United States proved to be less reliable than those produced by using a well-known econometric model or by averaging the predictions of a panel of business economists. These researchers argued that the indicator variables in combination produce reasonably good forecasts and that simple models based on single indicators fail to yield consistently useful information. Out of the nineteen indicators, only ten were consistently worse at forecasting inflation. They deduced that increases in commodity prices precede future declines in inflation. For example, an increase in price of oil by a dollar was associated with a drop in the annual rate of inflation of 0.22 percentage points after four quarters.

Research done by Christoffersen and Wescott (1999) examined the statistical linkages between monetary policy instruments and inflation. Inflation indicators were analysed and conclusions drawn by using one of the econometric methods of data evaluation. The Dickey-Fuller (ADF) tests were used and the results were not satisfactory for using one variable than incorporating all the variables. It was noted that including more than one lag the power of the ADF tests dropped and the null hypothesis was not rejected. This signifies that incorporating more variables could yield better results. The results stated that there is a logical linkage between the exchange rate and the inflation measures. Secondly, that there is some evidence movements in broad money that may influence certain representation of inflation. These relationships were predicted to be strong and tight by using the Bivariate Granger Tests. A range of inflation indicators were used and these includes monetary aggregates, interest rates, the exchange rates, real activity variables, labour market variables, foreign price indices and other financial market variables.

Research done by Kozicki (2001) in the United States using five indicators of inflation (interest rates, output, exchange rates, money supply (M3) and unemployment) concludes that no single economic indicator is always reliable. This evidence supports an approach to policymaking that involves monitoring a wide range of economic indicators. The author also found that results might differ in prediction of inflation depending with the monetary policy procedures, economic experiences and economic structure across each country on observation. Kozicki deduced that indicators based on nominal interest rate levels perform poorly although other interest rate indicators perform very well. On the other hand, unemployment rate predicted inflation very well.

Marques et al (2002), using United States data from the period 1983/1 to 2000/12 (18 years of monthly data) found that the "excluding food and energy" indicator is not an attractor of inflation. Their study found that the trimmed mean and the weighted median are weakly exogenous and are leading inflation indicators in United States. The excluding food and energy indicator was found to be a lagging rather than a leading inflation indicator. The authors concluded that the trimmed mean and the weighted median constitute useful core inflation indicators to be used by analysts or by the Central Bank in the assessment of recent price developments and in the analysis of the risks for future price stability. This was not, however, the case of the 'excluding food and energy' indicator, which behaved as a lagging rather than as a leading indicator of inflation.

Armour (2006) did a statistical evaluation of various measures of core inflation for Canada focusing on the inflationtargeting period from 1992 to 2003. The author used the following measures: lack of bias, low variability relative to total CPI inflation, and ability to forecast actual and trend total CPI inflation in the evaluation process. Armour found that although the traditional statistical measures of core inflation do satisfy properties useful for an operational measure of target inflation and that their usefulness is nevertheless limited, the measures were less volatile than total CPI and provide limited information to help predict total $\mathrm{CPI}$ inflation. However, the author also found that these measures are not immune to temporary relative price shocks meaning monitoring several different measures of core inflation should help economists to understand the various shocks hitting the economy. Therefore, the central bank of Canada may continue to 
use these measures as part of its analysis, but their limitations need to be acknowledged.

Massimiliano and Anindya (2005) studied a thorough analysis of leading indicators for Euro-area inflation and GDP growth. The authors considered many single (European and US) indicators, factors extracted from the set of indicators, groups of indicators or factors with the final specification determined by an automated model selection procedure and pooled forecasts. The comparison of the forecasting models used was conducted with respect to an autoregressive model, both ex post and in a pseudo-real-time context based on their performance for up to one-year and up to two-year forecasts. The authors argued that such a loss function, the RMSE-h criterion, is particularly relevant in a policy-making context. A major observation was that both for inflation and GDP growth, ex-post, autoregressions are systematically beaten by univariate leading indicator models, but the best indicator changes over time. This reflects the fact that in forecasting practice, although some groups of indicators perform robustly, it is advisable to update continuously the choice of indicators or groups of indicators. Moreover, the dynamics of the variable forecast will be driven by different shocks at different points of time, so that different indicators will assume different relevance over different time periods. Thus, even in the best-case scenario under ex-post evaluation autoregressions (sufficiently differenced for stationarity), which are simple models, are hard to beat consistently with a single forecasting model and overall provide a robust forecasting tool.

Sanchez-Fung (2003), studied the information content of monetary and open economy indicators in the conduct of monetary policy in two inflation targeting Latin American economies, that is Chile and Mexico. The main findings of the analyses revealed that for Chile both the real money gap and real money growth indicators contain significant information on deviations of inflation from the inflation target. In contrast, for Mexico different measures of the real exchange rate were found to be consistently relevant in the pre and post-inflation targeting (1999) periods. The author concluded that the results are of considerable importance to policymakers as they convey that neglecting the role that monetary and open economy indicators play in monetary policy making within an inflation targeting framework could be detrimental to the successful operation of an inflation targeting strategy.

\subsection{Why use inflation indicators to target inflation?}

If inflation indicators are not well considered, they can fail to predict inflation. Some indicators of inflation can yield good results in short term horizons and some in the long-term horizons. Therefore, there is always a need for considering all inflation indicators to predict inflation in either the short run or the long run. Some of the inflation indicators can contain information that is more relevant in the immediate future where as others may be more relevant on an intermediated horizon. Inflation indicators help policymakers to monitor signals from a range of indicators and to know whether these indicators of inflation consistently fail to predict inflation. If this is the case, then this will result in dropping these inflation indicator variables in predicting the rate of inflation.

If inflation indicators are well incorporated, they provide precise inflation predictions. A full knowledge of the inflation indicators on the rate of inflation will therefore be of great significance to the SARB in forecasting inflation and that focusing core inflation indicators will allow monetary authorities to prevent themselves from being misguided by the effects of temporary shocks on the evolution of the Consumer Price Index.

According to Figueiredo and Staub (2001), the analysis and evaluation of the individual inflation indicator to the prediction of inflation rate helps to eliminate temporary fluctuations from consumer price index allowing monetary authorities to identify shocks hitting the inflation rate that do not affect the trend inflation. Temporary shocks, despite influencing the headline index, are quickly reversed without affecting expectations and, therefore, do not demand a policy response from the monetary authority.

In this research paper, an employment of cointegration modelling has been carried out to determine if there is longterm relationship between the inflation rate and the inflation indicators. The purpose of this contribution is to examine the inflation rate and the inflation indicators in South Africa and investigate whether the inflation indicators move in a tandem with the inflation rate.

\section{Theoretical Framework and Model Specification}

\subsection{Data sources and definitions of indicator variables}

Quarterly secondary data covering the period 1997:Q2 to 2008:Q3 has been used. Data after 2008 has not been included because of the change of the SARB monetary stance due to the global financial crisis of 2008. Inflation targeting depends on a forecast of how inflation will develop assuming that monetary policy is unchanged also on an estimate of how future 
inflation is likely to be affected by a change in the current setting of monetary policy instruments. Therefore, the data after 2008 has not been included in this study. With the financial crisis, the SARB has been following a more flexible monetary policy regime placing more emphasis on economic growth and financial stability.

The global financial crisis has exerted a significant impact on central banks in the both the developed and developing world. South Africa has not avoided the ripple effects of the crisis although it has avoided the full-fledged banking crisis taking place in a number of countries. The study looks at the initial phase of the explicit inflation targeting regime in South Africa which lasted until the end of 2008 when the global financial crisis began. According to Van Der Merwe (2004), before the announcement of inflation targeting as a monetary policy in South Africa in 2000, an informal inflation targeting was already applied by the South African Reserve Bank. Burger et al (2009) also examines time when the SARB used the unofficial (implicit) inflation target regime in South Africa within the period 1990-2000 with the time when the SARB used the official inflation targeting. This made this study to lag back to three years back prior to the public announcement of inflation targeting. This period of informal inflation targeting brought light and confidence that formal inflation targeting will work and bring price stability to the South African economy.

Van Der Merwe (2004) states that success was achieved with informal inflation targeting in bringing the inflation rate down to lower levels in the 1990s as it moved below double digits in December 1992 and declined to an average annual rate of 5,2 per cent in 1999. It is believed that an emphasis was placed on the attainment of price stability but the time period over which it was to be achieved was not specified. This means that the monetary policy stance one way or another was altered by this decision. The framework differed from formal inflation targeting because growth in money supply was the intermediate target used which anchored monetary policy decisions by this period of informal inflation targeting. The SARB closely monitored developments in other financial and real indicators in reaching a decision on the appropriate level of short-term interest rates. Therefore an evaluation of the inflation rate should also include part of this period in which the Reserve Bank of South Africa used the informal targeting.

The data source is the South African Reserve Bank database. The cpix index has been defined as the headline consumer price index excluding food and non-alcoholic beverages, home owner's costs and value-added tax and the data has been retrieved from the Statistics South Africa (SSA). The methodology of core inflation excludes the elements whose short-term behaviour and differs from the underlying price trends. Thus this research has considered the fact that in the short run, the changes in indicator variables may not necessarily change the rate of inflation immediately as they behave at that moment. Therefore a long term trend has to be examined to find whether the inflation indicator variables are a true replica of the rate of inflation in South Africa.

The following is a list of the inflation indicators that has been employed along with their definitions:

An oil price, oil, refers to the price per barrel of Brent crude oil and is available from the SARB on a quarterly base. Money supply, M3 is the quarterly average of monthly Money supply, M3 data on the SARB website. The exchange rate, exch, is the foreign exchange rate South Africa cent per USA dollar using middle rates (R1 = 100 cents) on a quarterly base from the SARB website. The total employment, empl, rate is found by finding the aggregate of private and public employment rates from the SARB website. Gold price, gold, explains the price of gold and is shown also on a quarterly base from the SARB website. The interest rates, inte, is the money market interest rates available on the SARB website. The total interest rates were calculated by averaging the different interest rates to reach quarterly data. The data for interest rates starts on the forth quarter of 1998. The reason being that a new system of monetary accommodation was introduced with daily tenders of liquidity through repurchase transactions early 1998.

\subsection{Empirical methodology and results}

\subsubsection{Model specification and robustness}

The study employed econometric models to empirically evaluate each of the inflation indicator variables. The overall inflation model that has been estimated in this study uses a VAR based method employing time series data for the period 1997:Q2 to 2008:Q3. The period under study is the initial phase of the explicit inflation targeting regime in South Africa that lasted until the end of 2008 when the global financial crisis began. Of which after the crisis, the SARB followed a more flexible monetary policy regime, placing more emphasis on economic growth and financial stability. The following cointegration regression has been considered as been used by Cecchetti 1995; Marques et al 2000; Cecchetti et al 2000; Freeman 1997:

$\pi_{t+l, t+k}=a(L) \pi_{t-1}+b(L) x_{t-1}+\mu_{t}(l, k)$.

Where; $\pi_{t}=$ (cpix) represents the rate of inflation. 
$\pi_{t+l, t+k}=$ is the inflation from $t+l$ to $t+k$,

$x=$ is the inflation indicator (M3, gdp, oil, exch, empl, cpix)

$L=$ represents the lagged values of the inflation rate and the inflation indicator variable and equation (2) will only be stationary if $\mu_{t}$ is equal to zero.

The value of (cpix) is the measure that the South African Reserve Bank (SARB) uses when considering the interest rate level for money that the SARB lend to commercial banks known as the repo rate (initially, the inflation target was set to keep the Consumer Price Index excluding mortgage costs (CPIX) - a key indicator of inflation - between 3\% and 6\% average per annum), M3 is the total money supply, empl the number of people employed in the particular point of study, oil is the price oil, gdp is output growth and exch is the exchange rate as defined above. The short-run increases in oil prices, gold prices, output, employment, money supply (M3), and the exchange rates may not essentially signal an ensuing rise in the general price level. The level of each of these inflation indicators may not drift too far apart from the price level in the long term, that is, they may be cointegrated. This can be only if there is a dynamic relationship between each of the inflation indicators and the inflation rate. An error-correction model can then be formulated. The predictive performance of gold prices, interest rates, total employment, oil prices, output growth and M3 against the rate of inflation (cpix) using an approach based on cointegration and error-correction modeling can then be examined. As will be reviewed below, the results have been surprisingly encouraging as the coefficients of all the indicator variables are significant and this enhances the predictive value of the model. Given the statistical significance of the coefficients of all the indicator variables towards the rate of inflation, the above model should not be rejected.

\subsection{Data analysis}

In analysing data, for robust results, stationarity tests using the Augmented Dickey Fuller and Phillips-Perron tests has been carried out to check if the random time series is stationary. Cointegration tests using the Johansen approach (1988) has been conducted to see if there is a long term relationship between the variables. Two tests has been used to determine the number of cointegrating vectors: the trace test and the maximum eigen value test.

\subsubsection{The economic relationship between the inflation rate and the inflation indicators}

The inflation indicator variables are all consistent with the economic intuition. There is a negative relationship between the exchange rate and the inflation rate. As the inflation rate increases, the exchange rate falls (indicated by a negative coefficient of -0.1166). Depreciation of the rand leads to increased foreign demand for domestically produced goods and services through increased exports of goods and higher import prices that lead to inflation. Secondly, the price of oil is positively related to the rate of inflation (coefficient of 0.1261 ) indicating that an increase in the oil price will result in a surge in the rate of inflation. This is significant and is consistent with the economic theory. The results are similar to those by Burger and Marinkov 2009. The authors found that there is a positive link between the oil price and inflation in South Africa. This means that not only does an increase in the oil price contribute to a higher inflation rate with the effect not diminishing after the implementation of an official inflation targeting regime, but also leads to an increase in the quadratic forecast error of inflation. In other words, the price of oil and inflation are often connected in a cause and effect relationship.

The output growth is positively related to the rate of inflation which is also consistent with theory other studies like Girijasankar and Anis (2001). The authors find evidence of a long-run positive relationship between GDP growth rate and inflation for all four South Asian countries (Bangladesh, India, Pakistan and Sri Lanka). The coefficient of output growth in this study is positive 3.84. This undoubtedly states that a real increase in output growth would possibly result in an increase in the rate of inflation. As a result, it is called a procyclic (or procyclical) economic indicator. This simply means that it moves in the same direction as the economy. So if the economy is doing well, the coefficient will usually be increasing, whereas if there is a recession this indicator coefficient will be decreasing.

The money supply (M3) is also positively related to the inflation rate with the coefficient of 1.27 . This is economically significant and explains that the increases in money supply in the South African economy result in increases the inflation rate. The empl is positively related to d.cpix with a coefficient of 0.253204 . This is consistent with the theory and it means that a decrease in inflation would lead to an increase in the rate of unemployment. Therefore, unemployment is a countercyclic (or countercyclical) economic indicator as it moves in the opposite direction as the economy. The unemployment rate gets larger as the economy gets worse so it is a countercyclic economic indicator.

The interest rates are negatively related to the rate of inflation with a coefficient of -1.153 and this is consistent with theory which states that inflation rate and the real interest rate appear to move in opposite directions at all time. Inflation 
affects the time value of money, therefore, an anticipated change in inflation would lead to a corresponding change in interest rates. In case of a rise in inflation, lenders know that inflation will erode the value of their money over the term of the loan so they increase the interest rate to compensate for that loss. Lastly, the price of gold is positively related to the

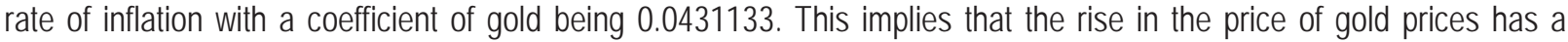
proportionate effect of increasing the rate of inflation in South Africa.

It can be deduced from the relationship between the inflation rate and the indicators of inflation that the output growth, the exchange rate, interest rates, money supply (M3) and the price of oil explains much of the variations of inflation rate in South Africa. These inflation indicators must be incorporated when predicting the inflation rate within the economy in South Africa under the inflation targeting regime. This evidently states that the monetary policy makers must incorporate these variables in forecasting the rate of inflation within the South African economy.

\subsubsection{Cointegration tests and error-correction modeling: Engle-Granger Test}

After establishing that the relevant variables are cointegrated, we then estimate an error correction model. In an errorcorrection model, the short-term dynamics of the variables in the system are influenced by the deviation from equilibrium.

From the data, for example, it shows that there exists a linear combination between the variables cpix and oil. Since these two variables are cointegrated, it means that they have an error correction representation. This means that the short-term changes in the cpix reflect not only its own past changes and those of the oil variable, but also current adjustment to correct for past deviations (errors) from the stable long-term relationship. This has been the case for all the other variables as can be seen from the results indicated. The research employed the procedure suggested by Johansen (1988) which provides a unified framework for testing for the number of cointegrating vectors. The values of the test statistic however, indicate that the null hypothesis of no cointegrating vector cannot be rejected at the $5 \%$ level over the period 1997:Q2-2008:Q3. The results of the Johansen tests are presented and the critical values for the Trace test at 5\% significant level is 15.41. The figures for the trace statistic reported are all significant at level of significance of $5 \%$ (results on Table 2). This shows that the all the variables are cointegrated with the cpix.

Table 1. Dickey-Fuller test for unit root

\begin{tabular}{|c|c|c|c|c|}
\cline { 3 - 5 } \multicolumn{2}{c|}{} & \multicolumn{3}{c|}{ Critical values } \\
\hline Variables & Test statistic & $1 \%$ & $5 \%$ & $10 \%$ \\
\hline Cpix & -7.517 & -3.621 & -2.947 & -2.607 \\
\hline Empl & -3.91 & -3.614 & -2.944 & -2.606 \\
\hline m3 & 11.03 & -3.614 & -2.944 & -2.606 \\
\hline Gold & -8.186 & -3.614 & -2.944 & -2.606 \\
\hline Gdp & 4.276 & -3.614 & -2.944 & -2.606 \\
\hline Oil & -5.426 & -3.621 & -2.947 & -2.607 \\
\hline Exch & -5.056 & -3.614 & -2.944 & -2.606 \\
\hline Inte & -4.222 & -3.662 & -2.964 & -2.614 \\
\hline
\end{tabular}

Table 2. Johansen tests for cointegration

\begin{tabular}{|c|c|c|}
\cline { 3 - 3 } \multicolumn{2}{c|}{} & Critical values \\
\hline Variables & Trace statistic & 5\% level of significance \\
\hline Empl & 33.1263 & 15.41 \\
\hline m3 & 41.9422 & 15.41 \\
\hline Gold & 45.8039 & 15.41 \\
\hline Gdp & 39.9189 & 15.41 \\
\hline Oil & 28.9418 & 15.41 \\
\hline Exch & 33.5826 & 15.41 \\
\hline Inte & 39.1175 & 15.41 \\
\hline
\end{tabular}

\subsection{Policy implications based on cointegration results}

Through rigorous time series analysis, the research found that there is a long run relationship between the inflation indicators and the rate of inflation. The analysis confirms that inflation indicator variables are an exceptional policy tool to 
determine the rate of inflation in the long run in South Africa in line with this research paper's hypothesis. The indicator variables selected are a true replica of the cause of inflation in South Africa. These indicators of inflation may give the direction to what trend will the rate of inflation follow in the long-run given they are correctly incorporated in the prediction of inflation. In predicting and targeting inflation, the inflation indicators must be incorporated for excellent forecasting of inflation rate.

\section{Conclusions, Recommendations and Areas for Further Research}

Inflation indicators have been subject to study in countries that had adopted inflation targeting as seen from the studied literature in this research paper. The relationship between the inflation rate and its indicators is essential for different groups/stakeholders within the economy. It is against this particular background that it was necessary to investigate the relationship between the rate of inflation and its indicators. The overall objective or the primary concern of this study was to investigate whether there is a long-run relationship between the rate of inflation and its indicators in South Africa.

This study considered theoretical literature from different papers that evaluated inflation indicators using different methods of evaluation. In this study a number of different theoretical literature reviews has been reviewed. Some of these studies used econometric models to test whether there is a constant long-run relationship between the rate of inflation and the inflation rate empirically. The majority of these studies found that most of the indicators of inflation have a long term relationship with the rate of inflation reflecting that the indicators are useful in the determination of inflation in a given economy.

In order to determine the long run relationship between the rate of inflation and the inflation indicators, the Johansen cointegration and error correction methodology was preferred to other techniques because of the merits to other methodology.

Johansen cointegration tests provided evidence that there is one cointegrating vector. Evidence of cointegration allowed the estimation of VECMs, which provided the parameter estimates for the long run relationships. All the variables had been found to have a long run relationship with the rate of inflation.

\subsection{Conclusion}

The main conclusion of this paper is broadly in line with several existing studies. The empirical results provided in this research support for an approach to policymaking that involves collecting, monitoring, and analysing a wide range of economic indicators. The results suggest that focusing attention too narrowly on one or a few indicators could be risky since the ability of any given indicator to predict inflation varies across different economic environments. A conclusion can be brought to light that all the inflation indicators are cointegrated with the inflation rate and may be useful in the determination and targeting inflation. There is a long run relationship between the inflation rate, the prices of oil, the employment rate, interest rate, the exchange rate, the money supply (M3) and the price of gold in South Africa. Although this might be the case, the policy makers must strive to use these results as a yardstick to decision making and may be a useful tool in forecasting inflation. Within the context of the outcomes detailed herein, and in line with the conclusions of the different scholars, this study recommends the continual use of inflation targeting as a monetary policy for the South African Reserve Bank in anchoring inflation expectations and inflation variability.

It is then possible to conclude that the announcement of inflation targets in South Africa is essential as it communicates the central bank's intentions to the financial markets and to the public and in so doing helps to reduce uncertainty about the future course of inflation. It is also crucial for the central bank to be able to convince the public that the inflation targeting framework will take precedence over other policy goals in case of conflict in South Africa. Since the inflation indicators evaluated have been found to be useful in the prediction of inflation in South Africa, it is therefore important to note that the targeting of one of the indicators will not provide a good monetary stance. For example, focusing narrowly on exchange rate stability is risky as the exchange rate instead of the inflation target may become the nominal anchor of monetary policy. This could lead to a tightening of monetary policy at times when inflation expectations and forecasts do not suggest that inflationary pressures are increasing, or vice versa. Too much concern about exchange rate stability can induce a wrong policy response. Targeting the exchange rate only is likely to worsen the performance of monetary policy and could under certain circumstances even lead to a recession in an economy.

On the other hand, it is possible to conclude that decision making on the appropriate monetary policy stance is not always easy and clear. For instance, where economic growth is well below potential, with rising inflation and an appreciating foreign currency, it is not so easy to decide on the appropriate monetary policy stance. Lowering of interest rates could only benefit on economic growth and weakening of the foreign currency value consequently leading to a 
further acceleration in inflation in this case. All in all it means that there is no appropriate indicator of inflation that can be targeted to keep the rate inflation in track and to very minimum positive value. A combination of all the indicator variables in this case in forecasting inflation would be recommended.

\subsection{Recommendations}

The effects of inflation indicators on the rate of inflation using South African data during the phase of SARB's inflationtargeting monetary policy regime were investigated. Very few previous studies have empirically investigated the effects of inflation indicators during an inflation-targeting monetary policy period. Thus, this paper is an attempt to fill this gap and to uncover the variety of interesting relationships specific to an inflation-targeting era. The important part is the identification and analysis of the various inflation indicators in relation to the rate of inflation. The study concluded that the inflation indicators move in tandem with the rate of inflation in the long run with the output growth, the exchange rate and the price of oil explaining much of the variations of inflation rate in South Africa. Amid high global fuel and food prices threatening to derail monetary-policy plans, the SARB need to clearly identify and communicate their inflation targets or risk undermining their credibility in the markets. I would recommend that the Reserve Bank should continue pursuing inflation targeting as it is still reaping good fruits according to these results obtained in this study. Inflation targeting has proved to be an efficient way of anchoring inflation expectations in South Africa. Price stability according to these results obtained is inevitable. Although the evaluated ancient alternatives might be useful to the South African economy since there is no best monetary policy stance for an economy at all times, the inflation targeting framework is still proving to be a good measure for holding the inflation rate to lower levels although sometimes out of the target range.

\subsection{Limitation of the study and areas of further research}

Although some research findings and the results are consistent with other studies from different countries that studied inflation indicators, there are few shortcomings/drawbacks. Albeit there is evidence that the stated objectives were successfully achieved and it is a potentially worthwhile contribution to inflation targeting as a monetary policy in South Africa, the first limitation centres on the credibility of the data, which, having been sourced from the SARB, may not be as credible as when it was obtained as primary data. The motive behind the use of the secondary data from SARB is that the data have been worked on and therefore will be appropriate for this study. The other limitation of the study pertains to the interpretation of results where, with only one test having been assessed (cointegration), generalization of findings will also be equally limited.

For further study, the most interesting part will be comparing how other African countries' inflation indicators are performing compared to the performance of South African indicators. This will reflect how the South African economy is performing in relation to other countries that are also using the inflation targeting framework.

In conclusion, specific outcomes and recommendations that are both academic and practical value were clearly articulated. It further identifies specific areas of research with the potential to reinforce the outcomes.

\section{References}

Akinboade, O.A., Niedermeier, E. W. and Siebrits, F. K., (2001). South Africa's inflation dynamics: Implications for policy. Department of Economics, University of South Africa

Angeriz, A., and Philip, A., (2009). Inflation targeting: Assessing the evidence. Cambridge Centre for Economic and Public Policy, Department of Land Economy, University of Cambridge. JEL Classification: E31, E52

Angeriz, A., and Philip, A., (2007). Assessing the performance of inflation targeting lite countries. The World Economy. Vol. 30, No. 11, pp. 1621-1645 November 2007

Armour, J., (2006). An evaluation of core inflation measures. Research Department Bank of Canada, Ottawa, Ontario, Canada K1A 0G9. Bank of Canada Working Paper 2006-10

Aron, J., and Muellbauerb, J., (2007). Review of monetary policy in South Africa since 1994. Journal of African economies, volume 16, N 5, pp. 705-744

Aron, J., and Muellbauerb, J., (2000). Estimating monetary policy rules for South Africa. University of Oxford, England. Central Bank of Chile Working Papers number. 89

Bermingham, C., (2009). Quantifying the impact of oil prices on inflation. Quarterly Bulletin 01 / January 09

Bernanke, B. S., and Mishkin, F. S., (1997). Inflation targeting: A new framework for monetary policy. Journal of Economic Perspectives, Volume 11, pp. 97116

Bernanke, B. S., Mishkin, F. S., Laubach, T., and Posen, A. S., (1999). Inflation targeting: Lessons from the international experience. Princeton, NJ: Princeton University Press

Bernd, H., and Carsten, H., (2001). Do we really need Central Bank independence? A critical re-examination. University of Basel, March 2001. WWZDiscussion Paper $01 / 03$

Billmeier, A.,(1999). The early years of inflation targeting. Review and outlook. Department of Economics, University of Bamberg, Germany. August 1999 
Boughrara, A., Boughzala, M., and Moussa, M., (2008). Are the conditions for the adoption of inflation targeting satisfied in Morocco? Abu Nawas Hotel Tunis, Tunisia,Working Paper 444

Bruce, B., (2006). Bundle SARB. (2006) 3. Record 534. Available at http://www.polity.org.za/polity/govdocs/commissions/2002/rand/part_i.pdf . Accessed on 06 May 2010

Bruno, M., and Easterly, W., (1998). Inflation crises and long-run growth. Journal of Monetary Economics 41: 3-26

Burger. P., and Marinkov, M., (2009). Inflation targeting and inflation performance in South Africa. Department of Economics, University of the Free State, JEL codes: E31, E52

Cabos, K., Funke, M., and Siegfried, N. A., (2001). Some thoughts on monetary targeting versus inflation targeting. German Economic Review 2(3): 218238

Carlstrom, T. C., and Fuerst. S. T., (2002). Monetary policy rules and stability: Inflation targeting versus price-level targeting. Federal Reserve Bank of Cleveland. February 15, 2002

Casteleijn, A. J. H., (1999). The viability of implementing an inflation targeting monetary policy framework in South Africa. Quarterly Bulletin, pp. 63-73

Casteleijn, A. J. H., (1998). South Africa's monetary policy framework. South African Reserve bank publications

Cecchetti, S. G., (1995). Inflation indicators and inflation policy. NBER Macroeconomics Annual, Vol. 10, pp. 189-219

Cecchetti, S. G., and Ehrmann, M., (1999). Does inflation targeting increase output volatility? An international comparison of policymakers' preferences and outcomes. NBER Working Paper 7426

Cecchetti, S. G., Steindel, C., and Chu, R., (2000). The unreliability of inflation indicators. Current issues in Economics and Finance, Vol. 6, number 4

Christoffersen, P. T. S., and Wescott, R., (2001). Is inflation targeting feasible in Poland? Economics of transition, vol 9, pp. 153-174

Christoffersen, P. F. S., and Wescott, R. F., (1999). Is Poland ready for inflation targeting? IMF working paper No. 99/41

Cooper, R. N., (1999). Exchange rate choice, Federal Reserve Bank of Boston in conference series. Issue Jun, pp. 99-136

Daniels, P. J., Nourzad, F., and VanHoose, D. D., (2004). Openness, centralized wage bargaining, and inflation. Working paper series, 2005-059-ECO

Davis, S., (2008). Inflation targeting in South Africa. Available at $h$ ttp://sharondavis.co.za/content/view/74/32/ . Accessed on 19 March 2010

Domenico, G., and Troy, D., (2007). A new core inflation indicator for New Zealand. International Journal of Central Banking. Reserve Bank of New Zealand. Discussion papers DP2008/17

Epstein, G., (2007). Central banks, inflation targeting and employment creation. Economic and labour market papers. Employment analysis and research unit economic and labour market analysis department 2007/2

Epstein, G., (2003). Alternatives to inflation targeting monetary policy for stable and egalitarian growth: A brief research summary. Working paper series Number 62

Fernando, A., Robert, E. L, Jr., and Warren, E.W., (2001). Interest rates and inflation. Federal Reserve Bank of Minneapolis Research Department. Working Paper 609

Figueiredo, M. R. F., and Staub, R. B., (2001). Evaluating core inflation measures for Brazil. Banco Central de Brasil. Working Paper No. 14

Fischer, S., et al., (2002). Modern hyper and high inflations. Journal of Economic Literature 40(3): pp. 837-880

Freeman, D. G., (1997). Do core inflation help to forecast inflation? Economics letters 58 (1998)

Girijasankar, M., and Anis, C., (2001). Inflation and economic growth: Evidence from four South Asian countries. Asia-Pacific Development Journal. Vol. 8, No. 1, June 2001

Gujarati, D.N., 2003. Basic econometrics 4th edition (4e). New York: McGraw-Hill Inc.

Johansen, S., (1991). Estimation and hypothesis testing of cointegration vectors in Gaussian vector autoregressive models. Econometrica. Vol 59 Pg $1551-$ 1580.

Johansen, S., (1988). Statistical analysis of cointegration vectors. Journal of economic dynamics and control. Vol 12 Pg 231-254.

Kozicki, S., (2001). Why do central banks monitor so many inflation indicators? Economic review. Third Quarter pp 5-42

Marques, C. R., Nevesa, P. D., and Sarmentoa, L. M., (2002). Evaluating core inflation indicators. Economic modelling 20 (2003) 765-775. JEL classifications: C43; E31; E52

Marques, R. C., Nevesa,D. P., da Silva, A.G., (2000). Why should Central Banks avoid the use of the underlying inflation indicator? Volume 75, Issue 1, March 2002, Pages 17-23

Massimiliano, M., and Anindya, B., (2005). Leading indicators for Euro-area Inflation and GDP growth. University of Ljubljana 2005

Mishkin, F. S., (2006). Monetary policy strategy: How did we get here? National Bureau of Economic Research. Working Paper 12515

Mishkin, F. S., (2004). Can inflation targeting work in emerging market countries? National Bureau of Economic Research. Graduate school of business, Columbia University

Mishkin, F. S., (2001). Inflation targeting. Graduate School of Business, Columbia University and National Bureau of Economic Research. Working paper No. W7926

Mishkin, F. S., (2001). Inflation targeting. Graduate School of Business, Columbia University and National Bureau of Economic Research. July 2001

Mishkin, F. S., (2001). Issues in inflation targeting, in price stability and the long-run target for monetary policy. Working paper 2001-24

Mishkin, F. S., (2000). Inflation targeting in emerging-market countries. The American economic review. Vol. 90, No. 2. Papers and proceedings of the one hundred twelfth annual meeting of the American Economic Association pp. 105- 109

Mishkin, F. S., and Schmidt-Hebbel. K., (2007). Does inflation targeting make a difference? National Bureau of Economic Research. Working Paper number12876

Mnyande, M., (2009). Inflation targeting in a time of financial and economic crisis - South Africa's experience. Presentation at the Wits Business School. 23 April 2009

Mukherjee, B., and Singer. A. D., (2008). Monetary institutions, Partisanship, and Inflation targeting. International Organization 62, Spring 2008, pp 323-58

Nelson, E., and Neiss, K. S., (2003). The real-interest-rate gap as an inflation indicator. Macroeconomic dynamics, 7, pp. 239-262

Neumann, J. M. M., and von Hagen, J., (2002). Does inflation targeting matter? The Federal Reserve Bank of St. Louis. July/August 2002

Sanchez-Fung, R. J., (2003). Inflation targeting and monetary analysis in Chile and Mexico. School of Economics, Kingston University, Penrhyn Road, Kingston upon Thames, Surrey, KT1 2EE, England, UK. JEL classification numbers: E30; E40; E50; F41

Svensson, L. E. O., (2007). Inflation targeting. Princeton University, CEPS working paper number 144

Van Der Merwe., (2004). Inflation targeting in South Africa. Occasional Paper No 19, July 2004. South African Reserve Bank Von Hagen, J., and Matthias, B., (2001). Monetary policy in unknown territory. The European Central Bank in the early years. ZEl, University of Bonn, Indiana University, and CEPR 